\title{
Major single nucleotide polymorphisms in polypoidal choroidal vasculopathy: a comparative analysis between Thai and other Asian populations
}

This article was published in the following Dove Press journal:

Clinical Ophthalmology

21 March 2012

Number of times this article has been viewed

\author{
Patchima Chantaren' \\ Paisan Ruamviboonsuk' \\ Mathurose \\ Ponglikitmongkol ${ }^{2}$ \\ Montip Tiensuwan ${ }^{3}$ \\ Somying Promso ${ }^{4}$ \\ 'Department of Ophthalmology, \\ Rajavithi Hospital, Bangkok, \\ ${ }^{2}$ Department of Biochemistry, \\ Faculty of Science, Mahidol \\ University, Bangkok, ${ }^{3}$ Department \\ of Mathematics, Faculty of Science, \\ Mahidol University, Bangkok, \\ ${ }^{4}$ Virology and Molecular Microbiology \\ Unit, Department of Pathology, \\ Faculty of Medicine, Ramathibodi \\ Hospital, Mahidol University, \\ Bangkok, Thailand
}

Purpose: To investigate the association in a Thai population between the major age-related macular degeneration (AMD) susceptibility loci, $Y 402 \mathrm{H}$ and $I 62 \mathrm{~V}$ in the complement factor $\mathrm{H}$ (CFH) and $A 69 S$ in the age-related maculopathy susceptibility 2 (ARMS2) genes, and polypoidal choroidal vasculopathy (PCV).

Methods: A case-control study included 97 PCV cases and 102 age- and gender-matched controls without any retinopathy. The genotypic profiles of the three polymorphisms were obtained using a real-time polymerase chain reaction assay. The allelic and genotypic association between the polymorphisms and PCV were compared with those from the compiled data of other Asian populations reported previously.

Results: Strong associations between the $Y 402 \mathrm{H}, \mathrm{I} 62 \mathrm{~V}$, and $\mathrm{A} 69 \mathrm{~S}$ polymorphisms and PCV were observed in the present study $(P=0.002,0.003$, and 0.0008 respectively $)$ and in the compiled data ( $P<0.0001$ for all three polymorphisms). The risk allele frequencies of the polymorphisms in PCVs and in controls from the present study $(15.0 \%$ and $5.4 \%$ for $Y 402 H, 71.7 \%$ and $57.4 \%$ for $I 62 \mathrm{~V}$, and $54.1 \%$ and $37.3 \%$ for $A 69 S$ respectively) were also comparable with the frequencies from the compiled data $(10.3 \%$ and $6.4 \%$ for $Y 402 \mathrm{H}, 75.2 \%$ and $58.3 \%$ for $I 62 \mathrm{~V}$, and $56.8 \%$ and $36.8 \%$ for $A 69 S$ respectively). The genotype distribution for each polymorphism was also comparable in both datasets.

Conclusion: The findings of this study support a significant genetic association between the major AMD susceptibility genes and PCV across Asian populations. This suggests that AMD and $\mathrm{PCV}$, despite different phenotypic manifestation, may share common genetic risk factors.

Keywords: genetic, association, PCV, age-related macular degeneration, $C F H$ gene, ARMS2 gene

\section{Introduction}

A significant association between single nucleotide polymorphisms (SNP) and age-related macular degeneration (AMD) has been reported in diverse populations worldwide. ${ }^{1}$ The two most common AMD-associated SNPs, the $Y 402 H$ polymorphism in the complement factor $\mathrm{H}(\mathrm{CFH})$ gene on chromosome 1q31 and the $A 69 S$ polymorphism in the age-related maculopathy susceptibility 2 (ARMS2) gene on chromosome 10q26, have been found in Caucasian and Asian populations. ${ }^{2,3}$ The phenotypic manifestation of AMD in a large number of Asian patients, however, are different from those in Caucasian patients. ${ }^{4} \mathrm{~A}$ variant of the neovascular form of AMD in Asians, known as polypoidal choroidal vasculopathy (PCV), has typical characteristics of an abnormal branching vascular network with terminal polypoidal bulbs in inner choroids, which are not commonly found in Caucasians. ${ }^{5}$ This has raised a question of whether genotypic manifestations of PCV are different from those of AMD.
Correspondence: Paisan Ruamviboonsuk Department of Ophthalmology, Rajavithi Hospital,

Bangkok 10400, Thailand

Tel +6626447000 ext 2810

Email paisan.trs@gmail.com submit your manuscript $\mid$ www.dovepress.con

Dovepress

http://dx.doi.org// 0.2/47/OPTH.S30529 
Initial studies on the association between these two genes and PCV among Asians have shown contradictory results. Although the A69S SNP has been widely found to exhibit a strong association with PCV in many Asian populations, studies in Japanese, Chinese and Korean populations could not find a significant link between $Y 402 H$ and AMD. ${ }^{6-8}$ Interestingly, few studies revealed an association between PCV and the $I 62 \mathrm{~V}$ polymorphism of another locus in the same $C F H$ gene. Recent studies in a Japanese population and a cohort of subjects of European-American descent in the United States, however, have shown a strong association between $\mathrm{Y402H}$ and PCV. ${ }^{9,10}$

The majority of these data have been obtained from East Asian populations, whereas data from other Asian countries are scarce. This study was conducted to validate the associations between the three SNPs, $Y 402 \mathrm{H}$ and $\mathrm{I} 62 \mathrm{~V}$ in $\mathrm{CFH}$ and A69S in the ARMS2 genes, and PCV in a Thai population. Since the Asian population comprises various ethnic groups that may differ in physical appearance, lifestyle, culture, religion, socioeconomic status, and genetic background, ${ }^{11}$ the results were compared with the compiled data of studies from other Asian populations. The results obtained in this study should provide an insight into the genotypic manifestations of PCV with additional data from a Southeast Asian population.

\section{Methods}

\section{Participants}

This study was conducted under approval of the Ethical Committee on Research Involving Human Subjects of Rajavithi Hospital, Bangkok, Thailand. All participants gave written informed consent. A total of 119 patients with PCV and 173 controls were enrolled at the Eye Clinic of the same institute.

The inclusion criteria for PCV were: (1) Thai native; (2) having clinical manifestations of PCV, such as the presence of orange-red subretinal nodules, hemorrhagic retinal pigment epithelial detachment, subretinal hemorrhage, or intraretinal or subretinal fluid with exudates; and (3) having a branching vascular network with terminal polypoidal dilation of choroidal vessels identified by indocyanine green angiography (ICGA). The polyps identified in ICGA should correspond with the orange nodules found in clinical examination. The inclusion criteria for controls were: (1) Thai native; (2) age $\geq 50$ years; (3) absence of serious systemic or known genetic-influenced diseases such as cancer, diabetes mellitus, and glaucoma; and (4) clinical absence of diseases of the vitreous, retina, retinal pigment epithelium and choroid, especially drusen, or retinal pigment epithelial abnormality.

The exclusion criteria for both groups were: (1) relatives of any enrolled patients with PCV or controls, (2) any ethnicity other than Thai, (3) any participants whose parents were not born in Thailand, and (4) any participants who did not sign the consent form.

Each participant underwent a comprehensive ophthalmic evaluation using a slit lamp biomicroscope including dilated fundus examination and color fundus photography. All participants with PCV further underwent optical coherent tomography and simultaneous fluorescein and ICGA using a scanning laser ophthalmoscope (Heidelberg Retinal Angiography $\mathrm{II}^{\circledR}$, Heidelberg, Germany) to confirm the diagnosis.

\section{Genotyping}

The genomic DNA was extracted from buffy coat using Compact Nucleic Acid Isolation Kit (MagNA Pure ${ }^{\circledR}$ Compact System, Roche Diagnostics, Mannheim, Germany). DNA concentration was measured and diluted to the final concentration of $50 \mathrm{ng} / \mu \mathrm{L}$ using a spectrophotometer.

The genotyping of the rs1061170 (Y402H), the rs800292 $(162 \mathrm{~V})$, and the rs10490924 (A69S) polymorphism were performed in a 480 LightCycler $^{\circledR}$ instrument (Roche Diagnostics) using a commercial real-time assay (LightMix ${ }^{\circledR}$, Roche Diagnostics). A $10 \mu \mathrm{L}$ reaction mixture was prepared in a 96-well polymerase chain reaction (PCR) plate containing $50 \mathrm{ng}$ genomic DNA, $0.5 \mu \mathrm{L}$ for probe-primers mix (LightMix for the detection of human SNPs, TIB MOLBIOL GmbH, Berlin, Germany), $1 \mu \mathrm{L}$ 2X LightCycler ${ }^{\circledR}$ FastStart DNA Master HybProbe (Roche Diagnostics), $2.7 \mu \mathrm{L}$ deoxyribonuclease (DNase)-free water (PCR-grade), and processed according to the manufacturer's instructions (Roche Diagnostics). Real-time PCR of each SNP was performed by an initial denaturation at $95^{\circ} \mathrm{C}$ for 10 minutes, followed by 45 cycles of $95^{\circ} \mathrm{C}$ for 10 seconds, $60^{\circ} \mathrm{C}$ for 10 seconds, and $72^{\circ} \mathrm{C}$ for 15 seconds. In order to determine the melting points after the amplification phase, a melting curve analysis was performed at $95^{\circ} \mathrm{C}$ for 30 seconds and at $40^{\circ} \mathrm{C}$ for 20 minutes, followed by a slow heating at the rate of $0.2^{\circ} \mathrm{C}$ per second until reaching $75^{\circ} \mathrm{C}$. The polymorphism was determined to have a specific melting point of $55^{\circ} \mathrm{C}$ for the risk and $62.5^{\circ} \mathrm{C}$ for the nonrisk allele.

In addition, nine blood samples were randomly selected for DNA sequencing analysis (Macrogen ${ }^{\circledR}$, Seoul, Korea) to confirm the genotyping results. 


\section{Statistical analysis}

The sample size was estimated using Quanto software ${ }^{12}$ with type 1 error set at 0.05 and power set at $80 \%$. The minor allele frequency applied for this estimation was based on the lowest frequency of the three investigated SNPs in Asians reported in the literature, which was the frequency of $Y 402 \mathrm{H}$ of $0.05 .^{13}$ The prevalence of PCV was based on that of neovascular AMD in Thailand, $0.2 \% .{ }^{14} \mathrm{PCV}$ was estimated to be $23 \%$ of this prevalence ${ }^{15}$ or $0.05 \%$. At least 85 participants were required in each study group using this estimation. The chi-square test was used for testing deviation of genotypic frequency from Hardy-Weinberg equilibrium. The Fisher's exact test was used to test the allelic and genotypic associations of each SNP with PCV. Statistical significance was considered at $P<0.05$.

Logistic regression analysis was used to estimate the odds ratio of having PCV for participants with the homozygous risk genotype compared with those who had the heterozygous, and homozygous nonrisk genotypes. Bonferroni correction was used for assessing the $P$-values obtained from these analyses.

For comparison with other Asian populations, data were compiled of association studies between the three SNPs and PCV in Asians published in the literature ${ }^{9,13,16-22}$ and calculated the association, allele frequency, and genotype distribution for each SNP using the same protocol. These compiled data gave sample sizes of 1291 PCVs and 2455 controls for $Y 402 H, 713$ PCVs and 1604 controls for I62 V, and 747 PCVs and 1331 controls for $A 69 S$.

\section{Results}

A total of 97 patients with PCV and 102 normal controls were included for genetic analysis. No significant difference between these two groups was found for the demographic characteristics (Table 1). No significant deviation from the Hardy-Weinberg equilibrium was found for each SNP in either study group. The DNA sequencing results of all nine random blood samples confirmed the genotyping results of this study.

\section{Risk allele frequency}

In the cohorts used in this study, the frequency of the risk allele for each SNP, C, G, and T for $Y 402 \mathrm{H}, \mathrm{I} 62 \mathrm{~V}$, and $A 69 \mathrm{~S}$

Table I Demographic characteristic of the study population

\begin{tabular}{llll}
\hline & $\begin{array}{l}\text { PCV } \\
(\mathbf{n}=\mathbf{9 7})\end{array}$ & $\begin{array}{l}\text { Controls } \\
(\mathbf{n}=102)\end{array}$ & P-value \\
\hline Gender (male/female) & $48 / 49$ & $50 / 52$ & $0.948^{\mathrm{a}}$ \\
Mean age \pm SD (years) & $62.9 \pm 8.9$ & $62.2 \pm 7.6$ & $0.595^{\mathrm{b}}$ \\
Age range (years) & $42-87$ & $50-86$ & \\
\hline
\end{tabular}

Notes: 'By z-test; 'by independent $t$-test.

Abbreviations: PCV, polypoidal choroidal vasculopathy; SD, standard deviation. respectively, were found to be similar to that in the compiled data. In addition, the frequency of the risk allele of each SNP was significantly higher in participants with PCV than in controls in both datasets (Table 2).

\section{Risk genotype}

Data in Table 3 show that the genotype distribution in this study's Thai population was similar to that in the compiled Asian population. The only exception was found for the frequency of the homozygous risk genotype (CC) of $Y 402 \mathrm{H}$ in the PCV group, which was higher in the present study's population (3.1\%) than in the compiled Asian population $(0.7 \%)$. These frequencies, however, were very low in both populations.

Compared with having the homozygous nonrisk genotype (TT), having the heterozygous genotype $Y 402 H$ (CT) significantly increased the chance (by approximately three times) of having PCV. Individuals with the homozygous risk allele of $I 62 \mathrm{~V}(\mathrm{GG})$ and $A 69 S$ (TT) were approximately 4-5 times as likely to have PCV as those with the homozygous nonrisk allele (Table 4).

\section{Discussion}

This study showed that both $Y 402 \mathrm{H}$ and $\mathrm{I} 62 \mathrm{~V}$ polymorphisms in the $C F H$ and the $A 69 S$ in the ARMS2 genes were strongly associated with PCV in the Thai population. The confirmed genotyping results by DNA sequencing of all nine random blood samples suggested that the dataset was homogenous and unbiased. The strong association of the three SNPs was also observed in the compiled data of previously published studies in other Asian populations.

The $I 62 \mathrm{~V}$ of $\mathrm{CFH}$ gene, rather than the $Y 402 \mathrm{H}$, was initially believed to be the SNP associated with PCV in the Asian population. ${ }^{13,20}$ The results of this present study, in a Thai population, as well as those in the compiled data indicated that both $I 62 \mathrm{~V}$ and $Y 402 \mathrm{H}$ SNPs were associated with PCV in Asians. This discordance might be due to the low frequency of $Y 402 \mathrm{H}$ in Asians compared with the higher frequency of $I 62 \mathrm{~V}$. There is no report on the association between $I 62 \mathrm{~V}$ and PCV or AMD in Caucasians.

Interestingly, the frequency of the risk alleles of the $Y 402 H$ and $A 69 S$ in Asian patients with PCV may be different from that in Caucasian patients with PCV. The frequencies of the risk allele $\mathrm{C}$ of the $\mathrm{Y} 402 \mathrm{H}$ in PCVs, $15.0 \%$ in the present study and $10.3 \%$ in the compiled data, were much lower than that in a cohort of subjects with PCV of European descent in the United States, which was $49.1 \% .^{10}$ This is also true for the risk allele $\mathrm{T}$ of the $A 69 \mathrm{~S}$. These allele frequencies in 
Table 2 The allele frequency for each single nucleotide polymorphism in this study and other studies in Asians

\begin{tabular}{|c|c|c|c|c|c|c|c|c|}
\hline & \multicolumn{3}{|l|}{ PCV } & \multicolumn{3}{|c|}{ Controls } & \multirow[t]{2}{*}{$P$-value } & \multirow{2}{*}{$\begin{array}{l}\text { Odds ratio } \\
(95 \% \mathrm{Cl})\end{array}$} \\
\hline & $\mathbf{N}$ & $\mathbf{C}^{\mathrm{a}}$ & $\mathbf{T}$ & $\mathbf{N}$ & $\mathbf{C}^{\mathrm{a}}$ & $\mathbf{T}$ & & \\
\hline \multicolumn{9}{|c|}{ Rs I06II 70 (Y402H) } \\
\hline Current study & 97 & 29 (I5.0\%) & $165(85.1 \%)$ & 102 & II (5.4\%) & $193(94.6 \%)$ & 0.0023 & $3.081(1.493-6.360)$ \\
\hline & \multicolumn{7}{|c|}{ studies } & $2.467(2.046-2.973)$ \\
\hline Gotoh et $\mathrm{a}^{19}$ & 204 & 47 (II.5\%) & $36 \mathrm{I}(88.5 \%)$ & $\mathrm{N} / \mathrm{A}$ & N/A & N/A & N/A & $\mathrm{N} / \mathrm{A}$ \\
\hline Lee et $\mathrm{al}^{20}$ & 72 & $10(6.9 \%)$ & 134 (93.1\%) & 93 & $10(5.4 \%)$ & 176 (94.6\%) & 0.6438 & I.3। (0.47-3.62) \\
\hline Kondo et $\mathrm{al}^{13}$ & 130 & $23(8.8 \%)$ & 237 (91.2\%) & 173 & 18 (5.2\%) & $328(94.8 \%)$ & 0.0770 & $1.77(0.93-3.35)$ \\
\hline Hayashi et $\mathrm{al}^{9, \mathrm{~b}}$ & 510 & $106(10.4 \%)$ & 914 (89.6\%) & 1342 & $176(6.6 \%)$ & $2508(93.4 \%)$ & $9.73 \times 10^{-5}$ & $\mathrm{~N} / \mathrm{A}$ \\
\hline \multirow[t]{2}{*}{ Nakanishi et al ${ }^{17}$} & 375 & $80(10.7 \%)$ & $670(89.3 \%)$ & 847 & 110 (6.5\%) & I 584 (93.5\%) & N/A & $\mathrm{N} / \mathrm{A}$ \\
\hline & $\mathbf{N}$ & $\mathbf{G}^{\mathbf{a}}$ & $\mathbf{A}$ & $\mathbf{N}$ & $\mathbf{G}^{\mathrm{a}}$ & $\mathbf{A}$ & & \\
\hline \multicolumn{9}{|c|}{ Rs800292 (162V) } \\
\hline Current study & 97 & 139 (7I.7\%) & 55 (28.4\%) & 102 & II 17 (57.4\%) & 87 (42.7\%) & 0.0034 & $1.879(1.238-2.854)$ \\
\hline $\begin{array}{l}\text { Compiled } \\
\text { studies }\end{array}$ & 713 & $1072(75.2 \%)$ & 354 (24.8\%) & 1604 & I87| (58.3\%) & | 337 (4|.7\%) & $<0.0001$ & $2.164(1.883-2.487)$ \\
\hline Lee et $\mathrm{a}^{20}$ & 72 & 109 (75.7\%) & 35 (24.3\%) & 93 & $113(60.8 \%)$ & 73 (39.2\%) & 0.0045 & $2.01(1.21-3.36)$ \\
\hline Kondo et $\mathrm{al}^{13}$ & 130 & 201 (77.3\%) & $59(22.7 \%)$ & 173 & 197 (56.9\%) & $149(43.1 \%)$ & $1.7 \times 10^{-7}$ & $2.58(1.80-3.69)$ \\
\hline \multirow[t]{2}{*}{ Hayashi et al ${ }^{9, b}$} & 511 & $762(74.6 \%)$ & $260(25.4 \%)$ & 1338 & $|56|$ (58.3\%) & II I 5 (4I.7\%) & $\mathrm{N} / \mathrm{A}$ & $\mathrm{N} / \mathrm{A}$ \\
\hline & $\mathbf{N}$ & $\mathbf{T}^{\mathrm{a}}$ & G & $\mathbf{N}$ & $\mathbf{T}^{\mathrm{a}}$ & $\mathbf{G}$ & & \\
\hline \multicolumn{9}{|c|}{ Rs I 0490924 (A69S) } \\
\hline Current study & 97 & 105 (54.1\%) & 89 (45.9\%) & 102 & 76 (37.3\%) & $128(62.8 \%)$ & 0.0008 & $1.987(1.33 \mathrm{I}-2.960)$ \\
\hline $\begin{array}{l}\text { Compiled } \\
\text { studies }\end{array}$ & 747 & 849 (56.8\%) & 645 (43.2\%) & $133 \mid$ & 980 (36.8\%) & $1682(63.2 \%)$ & $<0.0001$ & $\begin{array}{l}2.259 \\
(I .985-2.57 I)\end{array}$ \\
\hline Kondo et $\mathrm{al}^{18}$ & 76 & 95 (62.5\%) & 57 (37.5\%) & 94 & 71 (37.8\%) & 117 (62.2\%) & $5.7 \times 10^{-6}$ & N/A \\
\hline Lee et $\mathrm{al}^{20}$ & 72 & $80(55.6 \%)$ & $64(44.4 \%)$ & 93 & $72(38.7 \%)$ & 114 (6I.3\%) & 0.0027 & $1.98(1.24-3.15)$ \\
\hline Sakurada et $\mathrm{al}^{2 \mathrm{I}}$ & 109 & $139(63.8 \%)$ & 79 (36.2\%) & 85 & $60(35.3 \%)$ & $110(64.7 \%)$ & $<0.0001$ & $3.2(2.1-4.9)$ \\
\hline Gotoh et $\mathrm{al}^{22}$ & 55 & $6 \mathrm{I}(55.5 \%)$ & 49 (44.5\%) & 74 & 60 (40.5\%) & $88(59.5 \%)$ & 0.0058 & $2.0(1.21-3.29)$ \\
\hline Nakanishi et al ${ }^{17}$ & 375 & $418(55.7 \%)$ & $332(44.3 \%)$ & 847 & $627(37.0 \%)$ & $1067(63.0 \%)$ & $\mathrm{N} / \mathrm{A}$ & $\mathrm{N} / \mathrm{A}$ \\
\hline Fuse et $\mathrm{al}^{16}$ & 60 & $56(46.7 \%)$ & $64(53.3 \%)$ & 138 & $90(32.6 \%)$ & $186(67.4 \%)$ & 0.0077 & $1.80(1.17-2.80)$ \\
\hline
\end{tabular}

Notes: $P$-values by Fisher's exact test; aindicates the risk alleles; ${ }^{b}$ the allele frequency was calculated from the reported genotype frequency.

Abbreviations: $\mathrm{PCV}$, polypoidal choroidal vasculopathy; $\mathrm{Cl}$, confidence interval.

Asians with PCV (54.1\% in the present study and $56.8 \%$ in the compiled data) were higher than those in Caucasians with PCV (31.8\%). ${ }^{10}$

In addition, the minor allele frequency (the risk allele frequency in controls) in Asians may also be different from that in Caucasians. The data from this present study and the compiled data indicated that the frequency of the allele $\mathrm{C}$ of the $\mathrm{Y} 402 \mathrm{H}$ in controls was approximately $6 \%{ }^{9,13,17,20}$ This is comparable to the frequency of the allele $\mathrm{C}$ in controls, $5.1 \%$, from a meta-analysis of association between this SNP and AMD in Asians. ${ }^{23}$ A meta-analysis of association between this SNP and AMD in Caucasian populations, ${ }^{2}$ however, indicates a much higher frequency of this allele in controls, $34.9 \%$. For $A 69 S$, a meta-analysis of association between this $\mathrm{SNP}$ and $\mathrm{AMD}^{3}$ points out that the minor allele frequency is $38.7 \%$ in Asians but $21.6 \%$ in Caucasians.

These data suggest that although the frequency of $Y 402 \mathrm{H}$ or $A 69 S$ is not uniform in diverse populations, its attributed risk for AMD or PCV exists across them. This supports the notion that the genetic effects of disease-associated variants are usually similar across racial boundaries regardless of their diverse allelic frequency among different populations. $^{24}$

Although PCV is different from neovascular AMD in many aspects, such as the affected age group and response to photodynamic therapy, both diseases share some similarities. Both are diseases of abnormal choroidal vessels, and both respond to anti-vascular endothelial growth factor (anti-VEGF) agent by absorption of exudates and extravascular fluid. ${ }^{25,26}$ This response to anti-VEGF, along with evidence that elevated $\mathrm{C}$-reactive protein (CRP) levels is strongly associated with both PCV and AMD, ${ }^{27}$ suggests that inflammation plays a role in both diseases.

$\mathrm{CFH}$ is a critical negative regulator of complement activation and inflammation. The $Y 402 H$ variant is located within complement control protein 7 , one of the complement 
Table 3 The genotype distribution for each single nucleotide polymorphism in this study and other studies in Asians

\begin{tabular}{|c|c|c|c|c|c|c|c|}
\hline & \multicolumn{3}{|l|}{ PCV } & \multicolumn{3}{|l|}{ Controls } & \multirow[t]{2}{*}{$P$-value } \\
\hline & $\mathrm{CC}$ & CT & TT & $\mathrm{CC}$ & CT & TT & \\
\hline \multicolumn{8}{|c|}{ Rs I06 I I 70 (Y402H) } \\
\hline Current study & $3(3.1 \%)$ & $23(23.7 \%)$ & $7 I$ (73.2\%) & $0(0 \%)$ & II (I0.8\%) & 91 (89.2\%) & 0.002 \\
\hline Compiled studies & $8(0.7 \%)$ & 227 (19.5\%) & 926 (79.8\%) & 14 (0.6\%) & $268(11.7 \%)$ & $2000(87.6 \%)$ & $<0.001$ \\
\hline Gotoh et al ${ }^{19}$ & $2(1.0 \%)$ & $43(21.1 \%)$ & 159 (77.9\%) & N/A & N/A & N/A & N/A \\
\hline Lee et $\mathrm{a}^{20}$ & $0(0 \%)$ & $10(13.9 \%)$ & $62(86.1 \%)$ & I (I.I\%) & $8(8.6 \%)$ & $84(90.3 \%)$ & $\mathrm{N} / \mathrm{A}$ \\
\hline Hayashi et $\mathrm{al}^{9}$ & $5(1.0 \%)$ & $96(18.8 \%)$ & 409 (80.2\%) & $8(0.6 \%)$ & $160(11.9 \%)$ & II 74 (87.5\%) & N/A \\
\hline \multirow[t]{2}{*}{ Nakanishi et al ${ }^{17}$} & I (0.2\%) & $78(20.8 \%)$ & $296(79.0 \%)$ & $5(0.6 \%)$ & 100 (II.8\%) & 742 (87.6\%) & $3.4 \times 10^{-4}$ \\
\hline & GG & GA & AA & GG & GA & AA & \\
\hline \multicolumn{8}{|l|}{ Rs800292 (162V) } \\
\hline Current study & $46(47.4 \%)$ & 47 (48.5\%) & $4(4.1 \%)$ & 29 (28.5\%) & $59(57.8 \%)$ & $14(13.7 \%)$ & 0.005 \\
\hline Compiled studies & 331 (56.8\%) & 209 (35.8\%) & $43(7.4 \%)$ & $492(34.4 \%)$ & $690(48.2 \%)$ & 249 (I7.4\%) & $<0.001$ \\
\hline Lee et $\mathrm{al}^{20}$ & $41(56.9 \%)$ & 27 (37.5\%) & $4(5.6 \%)$ & $36(38.7 \%)$ & $4 \mathrm{I}(44.1 \%)$ & $16(17.2 \%)$ & 0.0175 \\
\hline \multirow[t]{2}{*}{ Hayashi et $\mathrm{al}^{9}$} & $290(56.8 \%)$ & I82 (35.6\%) & $39(7.6 \%)$ & $456(34.1 \%)$ & 649 (48.5\%) & $233(17.4 \%)$ & N/A \\
\hline & TT & GT & GG & TT & GT & GG & \\
\hline \multicolumn{8}{|c|}{ RsI 0490924 (A69S) } \\
\hline Current study & $2(33.0 \%)$ & I (42.3\%) & 24 (24.7\%) & 13 (I2.8\%) & 50 (49\%) & 39 (38.2\%) & 0.002 \\
\hline Compiled studies & 270 (36.1\%) & 309 (4I.4\%) & 168 (22.4\%) & $182(13.7 \%)$ & $616(46.3 \%)$ & $533(40.0 \%)$ & $<0.001$ \\
\hline Kondo et $\mathrm{al}^{18}$ & 31 (40.8\%) & 33 (43.4\%) & $12(15.8 \%)$ & $15(16.0 \%)$ & $4 \mathrm{I}(43.6 \%)$ & 38 (40.4\%) & N/A \\
\hline Lee et $\mathrm{al}^{20}$ & 25 (34.7\%) & 30 (4I.7\%) & 17 (23.6\%) & 12 (I2.9\%) & 48 (5I.6\%) & 33 (35.5\%) & 0.0034 \\
\hline Sakurada et $\mathrm{al}^{21}$ & 45 (4I.3\%) & 49 (44.9\%) & 15 (I3.8\%) & 14 (16.5\%) & $32(37.6 \%)$ & 39 (45.9\%) & $<0.0001$ \\
\hline Gotoh et $\mathrm{a}^{22}$ & $18(32.7 \%)$ & 25 (45.5\%) & 12 (21.8\%) & $12(16.2 \%)$ & $36(48.6 \%)$ & $26(35.1 \%)$ & N/A \\
\hline Nakanishi et al ${ }^{17}$ & 133 (35.5\%) & I52 (40.5\%) & 90 (24.0\%) & 113 (13.3\%) & $40 I(47.3 \%)$ & 333 (39.3\%) & $1.6 \times 10^{-14}$ \\
\hline Fuse et $\mathrm{al}^{16}$ & $18(30.0 \%)$ & 20 (33.3\%) & 22 (36.7\%) & $16(11.6 \%)$ & $58(42.0 \%)$ & 64 (46.4\%) & 0.0069 \\
\hline
\end{tabular}

Note: $P$-value by Fisher's exact test.

Abbreviation: PCV, polypoidal choroidal vasculopathy.

control protein modules that contain binding sites for CRP. ${ }^{28}$ Previous biological studies have shown that the risk allele variants of $Y 402 H$ have reduced affinity on the binding to CRP. ${ }^{29}$ This may indicate that both AMD and PCV share the same genetic risks manifested by dysregulation of the complement system.
The relationship between $A 69 S$ and AMD or PCV is not well understood. Earlier studies propose that the altered function of the putative mitochondrial protein LOC387715/ $A R M S 2$ by $A 69 S$ substitution increases the susceptibility to the aging-associated degeneration of macular photoreceptors. ${ }^{30}$ Another study, however, suggests that ARMS2 might not confer

Table 4 The likelihood of homozygous or heterozygous risk genotype having PCV in this study and in the compiled data from other studies in Asians

\begin{tabular}{|c|c|c|c|c|c|}
\hline \multicolumn{2}{|c|}{ Paired genotype } & \multicolumn{2}{|c|}{ Current study } & \multicolumn{2}{|c|}{ Compiled studies } \\
\hline & & \multirow{2}{*}{$\begin{array}{l}P \text {-value } \\
0.839\end{array}$} & \multirow{2}{*}{$\begin{array}{l}\text { Odds ratio } \\
8.96(0.46-176.24)\end{array}$} & \multirow{2}{*}{$\begin{array}{l}P \text {-value } \\
0.649\end{array}$} & \multirow{2}{*}{$\frac{\text { Odds ratio }}{1.234(0.516-2.952)}$} \\
\hline Rs I 061170 & CC vs TT & & & & \\
\hline \multirow[t]{2}{*}{$(\mathrm{Y} 402 \mathrm{H})$} & CT vs TT & 0.006 & $2.974(1.364-6.488)$ & $<0.001$ & $1.829(1.508-2.219)$ \\
\hline & CC vs CT & 0.869 & $3.43(0.16-72.04)$ & 0.513 & $0.675(0.278-1.637)$ \\
\hline Rs800292 & GG vs $A A$ & 0.005 & $5.5514(1.665-18.513)$ & $<0.001$ & $3.896(2.739-5.542)$ \\
\hline \multirow[t]{2}{*}{$(162 V)$} & GA vs $\mathrm{AA}$ & 0.087 & $2.7829(0.86 I-9.03 I)$ & 0.002 & $\mathrm{I} .754(\mathrm{I} .225-2.5 \mathrm{II})$ \\
\hline & GG vs GA & 0.025 & 1.991 (1.090-3.636) & $<0.001$ & $2.221(1.804-2.735)$ \\
\hline Rs I 0490924 & TT vs GG & 0.001 & $4.0(1.760-9.091)$ & $<0.001$ & $4.707(3.645-6.078)$ \\
\hline \multirow[t]{2}{*}{ (A69S) } & TG vs GG & 0.390 & $1.333(0.692-2.565)$ & $<0.001$ & I.59| (1.276-I.985) \\
\hline & TT vs TG & 0.005 & $3.002(1.396-6.454)$ & $<0.001$ & $2.957(2.344-3.731)$ \\
\hline
\end{tabular}

Notes: Logistic regression analysis was used to test the likelihood of homozygous or heterozygous risk genotype having PCV when paired with homozygous nonrisk genotype; odds ratios indicate significance at $P<0.0167$ (0.05/3, Bonferroni correction); the homozygous risk genotypes are in bold; the studies included in the compiled data are listed in Table 3.

Abbreviations: PCV, polypoidal choroidal vasculopathy; vs, versus. 
risk to AMD through the mitochondrial pathway. ${ }^{31}$ Additional analysis of the LOC387715/ARMS2 protein with Ala or Ser codon 69 and its function in vivo are needed to better understand its contribution to PCV or AMD pathogenesis.

Limitations in this study include the assessments of only three major SNPs associated with AMD. Other SNPs may also be associated with PCV. To the authors' knowledge there has been no genome-wide study to document other PCV-associated SNPs that may not be associated with AMD. The compiled data from previously published studies were set up only for comparison with the results of this study. The aim was not to conduct a meta-analysis of association between the three SNPs and PCV; therefore, there were no strong criteria for inclusion and exclusion of the studies into the compiled data. Although the results of this study suggest a trend toward association between the three SNPs and PCV, more data from other Asian populations and other ethnic groups are necessary.

Cigarette smoking has been found to be associated with $\mathrm{PCV}$, and there was possible interaction between the $\mathrm{Y} 402 \mathrm{H}$ and cigarette smoking on PCV. ${ }^{17}$ However, some studies on interaction between cigarette smoking and SNPs in AMD showed contradictory results. ${ }^{32-35}$ Smoking history was surveyed in the present study's participants, but the data were so varied and unreliable that they were not used for analysis. This is another limitation of this study.

In conclusion, the major AMD-susceptibility genes, $\mathrm{CFH}$ with $\mathrm{Y402H}$ and $I 62 \mathrm{~V}$ and $A R M S 2$ with $A 69 S$, are associated with $\mathrm{PCV}$ in a Thai population. The results are in concordance with those from the compiled data obtained from previous association studies in other Asian populations. This suggests that AMD and PCV may share the same genetic predisposition. A genome-wide association study for PCV will improve the identification of other possible PCV susceptibility genes. This genetic data will eventually lead to a better understanding of the pathogenesis of PCV.

\section{Disclosure}

The authors report no conflicts of interest in this work.

\section{References}

1. Katta S, Kaur I, Chakrabarti S. The molecular genetic basis of age-related macular degeneration: an overview. J Genet. 2009;88(4):425-449.

2. Thakkinstian A, Han P, McEvoy M, et al. Systematic review and meta-analysis of the association between complement factor $\mathrm{H} Y 402 \mathrm{H}$ polymorphisms and age-related macular degeneration. Hum Mol Genet. 2006;15(18):2784-2790.

3. Tong Y, Liao J, Zhang Y, Zhou J, Zhang H, Mao M. LOC387715/ HTRA1 gene polymorphisms and susceptibility to age-related macular degeneration: a HuGE review and meta-analysis. Mol Vis. 2010;16: 1958-1981.
4. Laude A, Cackett PD, Vithana EN, et al. Polypoidal choroidal vasculopathy and neovascular age-related macular degeneration: same or different disease? Prog Retin Eye Res. 2010;29(1):19-29.

5. Imamura Y, Engelbert M, Iida T, Freund KB, Yannuzzi LA. Polypoidal choroidal vasculopathy: a review. Surv Ophthalmol. 2010;55(6): 501-515.

6. Gotoh N, Yamada R, Hiratani H, et al. No association between complement factor $\mathrm{H}$ gene polymorphism and exudative age-related macular degeneration in Japanese. Hum Genet. 2006;120(1):139-143.

7. Chen LJ, Liu DT, Tam PO, et al. Association of complement factor $\mathrm{H}$ polymorphisms with exudative age-related macular degeneration. Mol Vis. 2006;12:1536-1542.

8. Kim NR, Kang JH, Kwon OW, Lee SJ, Oh JH, Chin HS. Association between complement factor $\mathrm{H}$ gene polymorphisms and neovascular age-related macular degeneration in Koreans. Invest Ophthalmol Vis Sci. 2008;49(5):2071-2076.

9. Hayashi $\mathrm{H}$, Yamashiro $\mathrm{K}$, Gotoh N, et al. $C F H$ and $A R M S 2$ variations in age-related macular degeneration, polypoidal choroidal vasculopathy, and retinal angiomatous proliferation. Invest Ophthalmol Vis Sci. 2010;51(11):5914-5919.

10. Lima LH, Schubert C, Ferrara DC, et al. Three major loci involved in age-related macular degeneration are also associated with polypoidal choroidal vasculopathy. Ophthalmology. 2010;117(8):1567-1570.

11. Nguyen TT, Adair LS, Suchindran CM, He K, Popkin BM. The association between body mass index and hypertension is different between East and Southeast Asians. Am J Clin Nutr. 2009;89(6): 1905-1912.

12. Quanto (computer program). Available from: http://hydra.usc.edu/GxE/. Accessed February 25, 2012.

13. Kondo N, Honda S, Kuno S, Negi A. Coding variant I62 V in the complement factor $\mathrm{H}$ gene is strongly associated with polypoidal choroidal vasculopathy. Ophthalmology. 2009;116(2):304-310.

14. Jenchitr W, Ruamviboonsuk P, Sanmee A, Pokawattana N. Prevalence of age-related macular degeneration in Thailand. Ophthalmic Epidemiol. 2011;18(1):48-52.

15. Sho K, Takahashi K, Yamada H, et al. Polypoidal choroidal vasculopathy: incidence, demographic features, and clinical characteristics. Arch Ophthalmol. 2003;121(10):1392-1396.

16. Fuse N, Mengkegale M, Miyazawa A, et al. Polymorphisms in ARMS2 (LOC387715) and LOXL1 genes in the Japanese with age-related macular degeneration. Am J Ophthalmol. 2010;151(3):550-556, e551.

17. Nakanishi H, Yamashiro K, Yamada R, et al. Joint effect of cigarette smoking, $\mathrm{CFH}$ and LOC387715/HTRA1 polymorphisms on polypoidal choroidal vasculopathy. Invest Ophthalmol Vis Sci. 2010;51(12): 6183-6187.

18. Kondo N, Honda S, Ishibashi K, Tsukahara Y, Negi A. LOC387715/ HTRA1 variants in polypoidal choroidal vasculopathy and age-related macular degeneration in a Japanese population. Am J Ophthalmol. 2007;144(4):608-612.

19. Gotoh N, Yamada R, Nakanishi H, et al. Correlation between $C F H$ $Y 402 \mathrm{H}$ and HTRA1 rs11200638 genotype to typical exudative agerelated macular degeneration and polypoidal choroidal vasculopathy phenotype in the Japanese population. Clin Experiment Ophthalmol. 2008;36(5):437-442.

20. Lee KY, Vithana EN, Mathur R, et al. Association analysis of $\mathrm{CFH}, \mathrm{C} 2$, $\mathrm{BF}$, and HTRA1 gene polymorphisms in Chinese patients with polypoidal choroidal vasculopathy. Invest Ophthalmol Vis Sci. 2008;49(6): 2613-2619.

21. Sakurada Y, Kubota T, Mabuchi F, Imasawa M, Tanabe N, Iijima H. Association of LOC387715 A69S with vitreous hemorrhage in polypoidal choroidal vasculopathy. Am J Ophthalmol. 2008;145(6): 1058-1062.

22. Gotoh N, Nakanishi H, Hayashi H, et al. ARMS2 (LOC387715) variants in Japanese patients with exudative age-related macular degeneration and polypoidal choroidal vasculopathy. Am J Ophthalmol. 2009;147(6): 1037-1041, 1041, e1031-e1032. 
23. Kondo N, Bessho H, Honda S, Negi A. Complement factor H Y402H variant and risk of age-related macular degeneration in Asians: a systematic review and meta-analysis. Ophthalmology. 2011;118(2): 339-344.

24. Ioannidis JP, Ntzani EE, Trikalinos TA. 'Racial' differences in genetic effects for complex diseases. Nat Genet. 2004;36(12):1312-1318.

25. Matsumiya W, Honda S, Bessho H, Kusuhara S, Tsukahara Y, Negi A. Early responses to intravitreal ranibizumab in typical neovascular agerelated macular degeneration and polypoidal choroidal vasculopathy. J Ophthalmol. 2011;2011:742020.

26. Saito M, Iida T, Kano M. Intravitreal ranibizumab for polypoidal choroidal vasculopathy with recurrent or residual exudation. Retina. 2011;31(8):1589-1597.

27. Kikuchi M, Nakamura M, Ishikawa K, et al. Elevated C-reactive protein levels in patients with polypoidal choroidal vasculopathy and patients with neovascular age-related macular degeneration. Ophthalmology. 2007;114(9):1722-1727.

28. Schmidt CQ, Herbert AP, Hocking HG, Uhrin D, Barlow PN Translational mini-review series on complement factor $\mathrm{H}$ : structural and functional correlations for factor H. Clin Exp Immunol. 2008;151(1): 14-24

29. Ding X, Patel M, Chan CC. Molecular pathology of age-related macular degeneration. Prog Retin Eye Res. 2009;28(1):1-18.
30. Kanda A, Chen W, Othman M, et al. A variant of mitochondrial protein LOC387715/ARMS2, not HTRA1, is strongly associated with agerelated macular degeneration. Proc Natl Acad Sci US A. 2007;104(41): $16227-16232$.

31. Wang G, Spencer KL, Court BL, et al. Localization of age-related macular degeneration-associated $A R M S 2$ in cytosol, not mitochondria. Invest Ophthalmol Vis Sci. 2009;50(7):3084-3090.

32. Chu J, Zhou CC, Lu N, Zhang X, Dong FT. Genetic variants in three genes and smoking show strong associations with susceptibility to exudative age-related macular degeneration in a Chinese population. Chin Med J (Engl). 2008;121(24):2525-2533.

33. Scott WK, Schmidt S, Hauser MA, et al. Independent effects of complement factor $\mathrm{H} Y 402 \mathrm{H}$ polymorphism and cigarette smoking on risk of age-related macular degeneration. Ophthalmology. 2007;114(6): 1151-1156.

34. Sepp T, Khan JC, Thurlby DA, et al. Complement factor H variant $\mathrm{Y} 402 \mathrm{H}$ is a major risk determinant for geographic atrophy and choroidal neovascularization in smokers and nonsmokers. Invest Ophthalmol Vis Sci. 2006;47(2):536-540.

35. Wang JJ, Ross RJ, Tuo J, et al. The LOC387715 polymorphism, inflammatory markers, smoking, and age-related macular degeneration. A population-based case-control study. Ophthalmology. 2008;115(4) 693-699.
Clinical Ophthalmology

\section{Publish your work in this journal}

Clinical Ophthalmology is an international, peer-reviewed journal covering all subspecialties within ophthalmology. Key topics include: Optometry; Visual science; Pharmacology and drug therapy in eye diseases; Basic Sciences; Primary and Secondary eye care; Patien Safety and Quality of Care Improvements. This journal is indexed on

Submit your manuscript here: http://www.dovepress.com/clinical-ophthalmology-journal

\section{Dovepress}

PubMed Central and CAS, and is the official journal of The Society of Clinical Ophthalmology (SCO). The manuscript management system is completely online and includes a very quick and fair peer-review system, which is all easy to use. Visit http://www.dovepress.com/ testimonials.php to read real quotes from published authors. 